Article

\title{
Rural Tourism Spatial Reconstruction Model from the Perspective of ATV: A Case Study of Mufu Township, Hubei Province, China
}

\author{
Hui Tao ${ }^{1}$, Zhihui Huang ${ }^{1, *}$ and Feixiao Ran ${ }^{2}$ \\ 1 School of Ethnology and Sociology, MinZu University of China, Beijing 100081, China; cgcbleach@163.com \\ 2 Central China Normal University, Wuhan 430000, China; rangrace@163.com \\ * Correspondence: zhihui1883@aliyun.com; Tel.: +86-138-1116-1415
}

Received: 11 June 2018; Accepted: 24 July 2018; Published: 30 July 2018

\begin{abstract}
This research argues that rural tourism areas can be divided into three kinds of spatial organizations, i.e., attractions (A), towns (T) and villages (V), and aims to address the increasingly serious problems of rural spatial disorders and ecological damage in the tourism-oriented urbanization process in China. It extracts the common features of the five spatial patterns based on ATV spatial benefit trade-offs and proposes a single-kernel spatial reconstruction model. The model emphasizes the moderate concentration of space utility and considers towns as the suppliers of tourism-supporting facilities, which prevents negative impacts arising from decentralized development. In addition, tourist attractions and villages are arranged by category, so as to protect the quality of the overall habitat. Taking Mufu Township as an example, the paper demonstrates the optimal reconstruction of ATV space and displays the effectiveness of spatial reconstruction in Mufu Township since 2009. Mufu Township has been rejuvenated. The single-kernel spatial reconstruction model not only builds the space management platform for Mufu Township, but also provides an operable theoretical basis for the reconstruction of new rural tourism spaces and offers the possibility of developing Chinese rural areas sustainably.
\end{abstract}

Keywords: rural tourism; tourism urbanization; ATV; space reconstruction; Mufu Township

\section{Introduction}

According to Lefebvre's [1] deconstruction of the space production theory, space is a powerful tool, with control and dominance. The rational construction of spatial elements is extremely beneficial to the sustainable development of economic structure, social relationships and the ecological environment. Rural areas have shown remarkable non-agricultural trends since the 1990s and gradually experienced a transformation from production spaces to consumption spaces [2]. Rural areas are spaces that can be revived through continuous construction and reconstruction [3]. In the past 30 years, tourism has become an important driving force for rural rejuvenation and spatial reproduction $[4,5]$. In the meantime, tourism urbanization has taken place in a growing number of villages in rural China [6]. Many traditional tourism destinations have developed into new service spaces where rural and urban areas are interpenetrated with each other, thereby highlighting the new features of tourism urbanization $[7,8]$. However, the socio-economic structure, resource allocation and the natural landscape element in rural areas have been significantly influenced [9]. The ecological environment load has increased and the rural space has become increasingly fragile [10]. Specifically, the corporate reconstruction of rural areas (the transformation of the tourism real estate) has triggered an extensive "land enclosure" movement (The forcible occupation of noncommercial land, such as farming land, for use for commercial purposes), leading to a large number of tourist facilities and damage to the 
overall appearance of rural areas. It has resulted in problems like hollow villages (HVs) [11], idle land resources and weak infrastructure. HVs are an important manifestation of Chinese rural decline that has resulted in numerous abandoned rural houses. The residents of HVs are mostly old people and children. In addition, rural characteristic crises have intensified and modern reconstruction, such as resettlement of residential areas, has brought additional damage to rural areas. These consequences are described by Mitchell [12] as creative destruction and summarized by Harvey [13] in a five-stage process: Early commodification, advanced commodification, early destruction, advanced destruction and post destruction. It is of great practical value and theoretical significance to study how rural areas respond to the impacts and vulnerabilities brought by tourism.

Subsequently, the reconstruction of rural space has become a new task of rural revitalization in China. Several studies have been conducted on the layout of rural tourism space. In particular, the study of spatial location of rural recreational facilities aims to find the balance between resource protection and ecotourism development related to urban, rural and resource-intensive areas [14]. However, these studies have the following deficiencies in the context of urban-rural integration: (1) Most studies ignored the transitional space between rural and urban areas caused by rural tourism, namely, rural tourism urbanization space; (2) little attention has been paid to the spatial coordination among tourism attractions, serving communities and villages; and, (3) studies on tourism boundaries in rural areas have been neglected, which caused the spatial disorder during the development of Chinese rural tourism.

To tackle these issues, this paper, for the first time, explores the spatial composition of tourism attractions (A), tourism towns (T) and villages (V) by using the spatial reconstruction model. Taking Mufu Township in Hubei Province as an example, it discusses and verifies the following aspects in small-scale space:

- New features of space: Spatial relations and functions of attractions, towns and villages.

- Spatial benefit trade-offs and development conditions of tourist attractions, towns and villages.

- Spatial reconstruction models based on ATV: Exploring scientific spatial reconstruction models on the premise of extracting the common features of rural tourism areas, thereby providing a theoretical basis for spatial management in rural areas with similar changes, and reconstructing spatial orders and landscape patterns of rural tourism destinations.

\section{Literature Review}

\subsection{Spatial Distribution and Sustainable Development of Tourism}

Studies on the relationships between rational spatial layout and sustainable ecological development [15-17] have been influenced by Howard's garden city theory [18]—an excellent exploration into "the peaceful path to real reform" through urban planning. Farrell [19] took the lead in researching sustainable tourism development and considered tourism destinations as complex and dynamic social-ecological systems. Subsequently, terms such as resilience and adaptive management have been used to explain issues such as the impacts of tourism [20], the responses to crises (climate change, disaster, etc.) [21] and the sustainable utilization of resources [22]. In terms of the environmental attitude related studies, humanistic geographers provided clear responses to social problems [23] and explored the impacts of the economy, lifestyles and physical environments on environmental values from multiple perspectives (i.e., space, place and individual experience) [24,25]. In the current century, Chinese scholars have mainly studied sustainable tourism from the perspectives of tourism space change [26], ecological security of tourism destinations [27], environmental carrying capacity [28], community participation in tourism development, and sustainable development models [29]. In addition, the studies have mostly focused on large and medium-scale areas. Scholars have attached great importance to the selection of spatial location and spatial layout in tourism destinations [30]. 
With the aggravation of ecological problems caused by spatial disorder, scholars have further expanded their research into sustainable tourism, mainly from the perspectives of tourism evolution processes, tourism environmental capacity, community participation, sustainable development models, etc. Since the 1970s, Chinese scholars have made advancements regarding the relationships between spatial layout and environmental protection, based on Clark's [31] recreation opportunity spectrum (ROS) theory and Gunn's [32] community attraction complex model, which have been internationally recognized and regarded as examples of small-scale tourism spatial layouts. For example, LAC (limits of acceptable change) [33], VERP (visitor experience and resources protection) [34] and CECOS (China's ecotourism opportunity spectrum) have become important bases for small-scale tourism space management [35], which safeguards the sustainable rights to scarce resources and strengthens the enclosure and visibility of spatial boundary networks, and is thereby regarded as the most powerful law for maintaining internal affairs.

\subsection{Spatial Production and Rural Reconstruction}

As a kind of power, space can promote production and create enclosure [36]. The emphasis on the impact of space on human activities and social environments is the sustainable development view of the man-land relationship advocated by traditional geographers [37-39]. For example, Dear [40] addressed the functions of physical geographic forms and special constructions in constituting, restricting and regulating the social life of human beings. Components and logical relations of rural space vary with tourism development patterns, types and scales [41].

Space obtains unprecedented features through constant construction, deconstruction and reconstruction under the influence of various factors [42]. The discussion of spatial reconstruction is essentially the organic exploration of social orders and space rights under the impact of urbanization on traditional civilization.

Judging from the evolution of research in academia, scientific management of space is of crucial significance to the success of rural social transformation and rural revitalization. Since the 1980s, new elements brought about by globalization have fitted into rural areas, giving rise to a new synthesis. This trend of construction does not diminish the internal impetus and development potential of rural areas. Instead, it is manifested as the on-going self-reconstruction driven by internal and external powers. An increasing number of international scholars have paid attention to rural reconstruction, consisting of settlement restructuring, socio-economic restructuring, spatial restructuring and cultural restructuring of rural geography. Among these aspects, spatial reconstruction has become the prominent research direction, in which research into the methodology of life-production-ecology space analyzes the restructuring mechanism of different spatial scales, contributing to the solution of current problems (e.g., improper development, spatial disorder and deterioration of the ecological environment). Moreover, some Chinese scholars have incorporated the reconstruction concept into broader fields, such as agri-tourism, rural destination development, rural landscape planning, transformation of traditional villages and tourism urbanization. Rural areas are being recognized as spaces that can be rejuvenated through long-term reconstruction, rather than simple geographical entities or appendices to urban areas.

\section{The Theoretical Perspective: ATV Spatial Collaboration}

\subsection{Spatial Attributes of the ATV}

Based on the introspection of the practical spatial problems brought about by rural tourism, this study mainly explores the alienation and the correlation among attractions, towns and villages in the process of tourism urbanization in rural areas. The research emphasis, therefore, is shifted from traditional tourism destinations to new tourism spaces that are regarded as the major development directions of rural rejuvenation [43]. Connotations of the three spatial organizations can be defined as follows: 
(1) Attractions (A): Tourism attractions are the core parts of the destination system and the production spaces of tourism destinations. A is mainly responsible for the implementation of tourists' activities and the creation of economic benefits.

(2) Towns (T): Towns (i.e., service supporting areas) are generally developed from market towns and central villages. They serve as the service core of the destination system and provide necessary infrastructure for local residents. In addition, towns tend to have existing and potential attractions that assume important functions of the tourism economy, including parks, entertainment venues, exhibition halls, conference centers, recreational hotels and resorts.

(3) Villages (V): Villages are the basic units of rural tourism, the radiation areas of local landscape images and the manifestations of tourism resources on man-made relationships. They constitute the tourism destination system with attractions and towns. Villages are responsible for the establishment of ecological security systems and the conservation of ecological landscapes (such as farmland, forests, grassland, waters, water sources and natural reserves).

Inspired by the ROS theory [31], the ATV perspective emphasizes the functional differences between spatial elements and represents the differential activities in the sustainable development of space (Figure 1). A is moderate in participation and anti-interference. $\mathrm{T}$ has the strongest anti-interference ability and undertakes the most intensive human activities. V is characterized by ecological vulnerability and low bearing capacity.

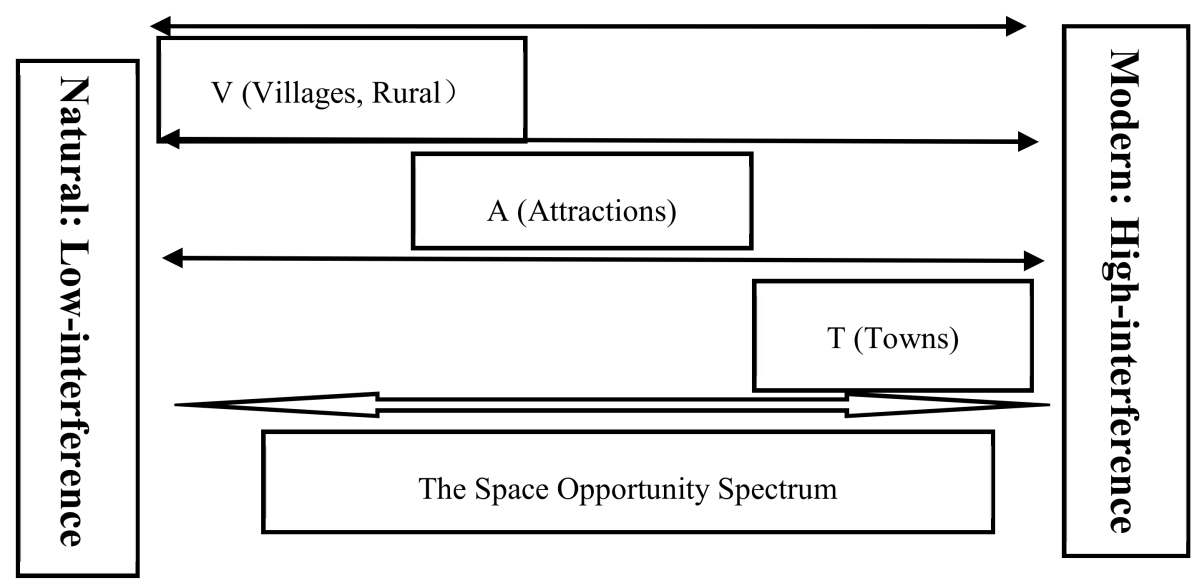

Figure 1. The Space Opportunity Spectrum of the ATV

\subsection{Functional Relationships of ATV}

$\mathrm{A}, \mathrm{T}$ and $\mathrm{V}$ are all independent and interdependent in the geographical space. Exclusive and diverse, these three elements jointly constitute the spatial cooperative system in tourism destinations [44].

The ideal functional relationships within the ATV eventually result in rural spatial collaboration (Figure 2). In reality, the complicated spatial relationships among $\mathrm{A}, \mathrm{T}$ and $\mathrm{V}$ are manifested in the following aspects. (1) Interactive coercing relationship between $\mathrm{V}$ and $\mathrm{T}$ : The development of small towns (service areas) prevents villages and surrounding areas from being crushed and occupied, exerting an impact on the original rural economy. In addition, the locality of villages affects the cultural manifestations of towns. (2) Cross collaboration between A and T: Traditional towns not only serve as tourist attractions, but also act as the suppliers of tourism facilities. A relies upon $\mathrm{T}$ to expand tourism and achieve the goals of resource conservation and intensive utilization when $\mathrm{A}$ is a protected area or natural environment with limited anti-interference ability. The abundance and quality of $\mathrm{A}$ directly affects the layouts and features of T. (3) Penetration and complementation between A and V: A originates from rural areas and integrates into the fundamental rural landscapes. Traditional villages 
enjoy significant humanistic value and serve as an important type of A. The tourism industry is almost the optimal choice for the sustainable development of traditional villages.

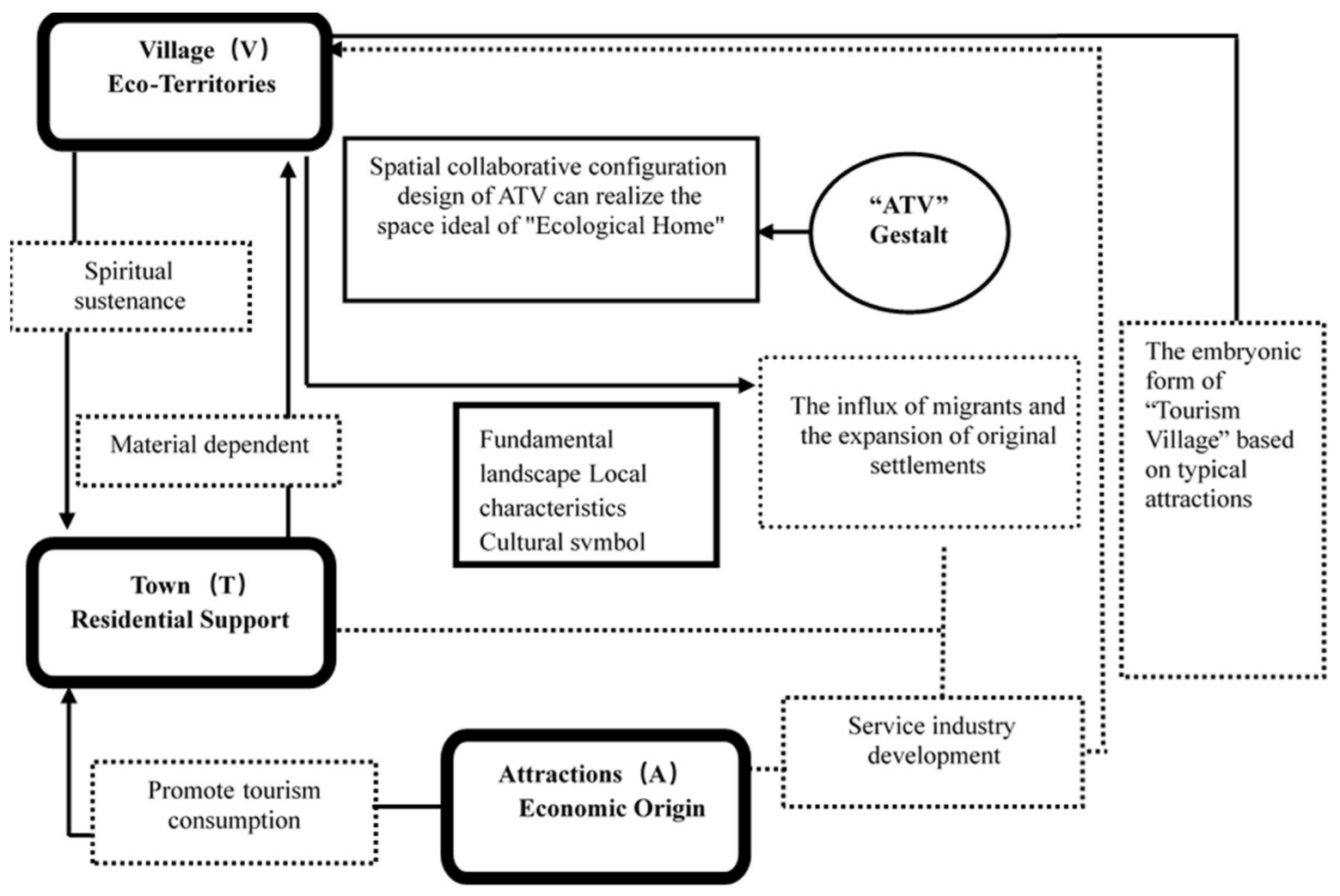

Figure 2. The spatial functions of the ATV

\subsection{ATV Spatial Collaboration and Rural Sustainable Development}

ATV spatial collaboration is a humanistic concern based on the overall value of rural landscapes. A can promote rural economic revitalization and improve the income sources of farmers. It should be noted that the construction of $\mathrm{T}$ is the key to rural environmental conservation. Scattered $\mathrm{T}$ will aggravate the fragmentation of construction land and damage the overall value of rural landscapes [45]. In the meantime, the cultural attributes of villages provide local contexts for the growth of tourist towns and offer sources for the sustainability of tourist attractions.

This perspective addresses the development of the tourism industry and the transformation of rural spatial elements. In a sense, these three spatial organizations represent the production-life-ecology of rural tourism destinations and the complex space evolved from industrial integration. As Figure 3 shows, the reconstruction of rural tourism areas depends on the construction of recreational environments, the improvement of service guarantee systems and the conservation of rural ecological environments. It is the optimized coordination of the environmental elements of tourist attractions, small towns and villages. In addition, rural reconstruction is inseparable from community involvement and government participation, as well as innovations in industries and management technologies.

Furthermore, great attention should be paid to the assessments of the ecological capacity of environmentally fragile areas (i.e., ecotourism areas/towns, areas with beautiful natural landscapes, national parks, etc.) during rural tourism development. The innovations of the ATV not only conserve the value of rural landscapes, but also adhere to the respect for original ecological cultural space in sustainable development. 


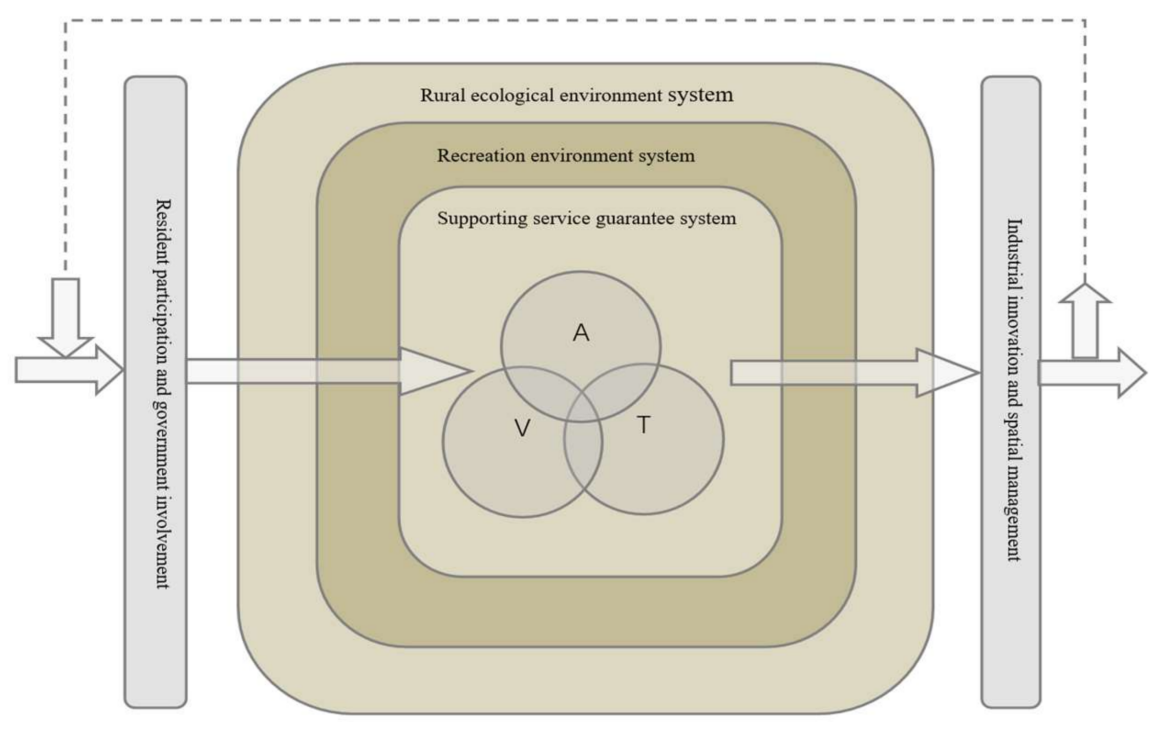

Figure 3. The sustainable development system of rural tourism areas.

\section{Spatial Reconstruction Models Based on the ATV}

\subsection{ATV Spatial Benefit Trade-offs}

The ATV perspective provides an opportunity for the rural spatial reconstruction. It pays attention to the combination of rural tourism spatial elements and considers ATV spatial benefit trade-offs to establish a new understanding of the tourism destinations. The term trade-off refers to the interactions among spatial attributes due to limited resources, which means that one functional advantage will be affected if another functional advantage is improved. $\mathrm{A}, \mathrm{T}$ and $\mathrm{V}$, as the three spatial elements of rural tourist areas, are responsible for developing different regional benefits. It is the core of spatial reconstruction to weigh the spatial benefit combinations of $\mathrm{A}, \mathrm{T}$ and $\mathrm{V}$, and explore the common features and spatial demands under different combinations.

The paper compares the advantages and disadvantages of $\mathrm{A}, \mathrm{T}$ and $\mathrm{V}$, respectively and constructs a three-dimensional space that consists of eight quadrants. The eight quadrants represent the eight kinds of ATV spatial benefit trade-offs separately.

According to the analysis, there are five kinds of space combinations that comprise the features of rural tourism destinations, as shown in Table 1 :

(1) The first quadrant $(\mathrm{A}+, \mathrm{T}+, \mathrm{V}+)$ is the ideal landscape state of the rural spatial combination. Due to its overlapping nature, ancient tourist towns require special attention in the process of space evolution, so as to avoid damage to the original environment. The emergence of new towns is a trend of future spatial optimization.

(2) The second quadrant $(\mathrm{A}-, \mathrm{T}+, \mathrm{V}+)$ mainly consists of artificial towns. For rural tourism destinations, it is necessary to reconstruct tourist attractions to improve the overall landscape quality. Theme towns are the best spatial reconstruction choice with the greatest market impact. Strengthening the protection of high-valued villages and agglomeration of various town businesses, therefore, are improvement directions for future studies.

(3) The third quadrant $(\mathrm{A}+, \mathrm{T}-, \mathrm{V}+)$ mainly consists of new tourist areas. It requires developing a tourism industry and modifying tourist facilities without damaging the rural environment. The best way to achieve this goal is to establish ecotourism areas and design the layout of the area with a single-kernel layout.

(4) The seventh quadrant (A+,T-, $\mathrm{V}-)$ mostly consists of scenic service areas. When developing tourist attractions, these are mainly designed for a group space layout while providing sightseeing, recreation and amusement. Villages (or residential areas) scattered around tourist attractions provide 
supporting services and gradually expand with market expansion. The construction of centralized service towns is the optimal choice for further regional development.

(5) The eighth quadrant (A+, T-, $\mathrm{V}-)$ mainly consists of tourist complexes and is mostly located in urban suburbs or rural fringes. For development purposes, market towns and surrounding service zones expand constantly in the initial development stage. Since the construction of tourism projects and supporting service facilities accelerates urbanization and the expansion of new towns, it is necessary to strengthen the restoration and spatial management of the original villages in the later stage.

Table 1. The analysis diagram of the spatial Gestalt Optimization based on the ATV relationship.

\begin{tabular}{|c|c|c|c|c|c|c|}
\hline Quadrant & $\mathbf{A}$ & $\mathbf{T}$ & $\mathbf{V}$ & Spatial Evolution Property & Gestalt Optimization & $\begin{array}{c}\text { Representative } \\
\text { Area Type }\end{array}$ \\
\hline I & + & + & + & $\begin{array}{l}\text { Ancient towns generally have highly attractive scenic spots, excellent } \\
\text { services, rich business formats and scientific trade-offs. They tend to } \\
\text { take into account all the three elements of ATV. With the development of } \\
\text { the tourism industry, ancient towns have developed into new-type } \\
\text { towns with new life functions. Influenced by industrial radiation, } \\
\text { surrounding rural settlements have evolved constantly. Peripheral rural } \\
\text { landscapes have been extended and villages have been } \\
\text { gradually urbanized. }\end{array}$ & & Ancient towns \\
\hline VII & + & - & - & $\begin{array}{l}\text { This kind of towns enjoys high-quality tourism resources and has high } \\
\text { demand for supporting services but no market towns. In addition, } \\
\text { service facilities are insufficient, residential areas are scattered and } \\
\text { environments are damaged. It is a high-level scenic spot that dominates } \\
\text { the expansion of service space. With the upgrading of the tourism } \\
\text { industry, rural service points have failed to meet market needs, leading } \\
\text { to the emergence of special tourist towns in surrounding areas. }\end{array}$ & & $\begin{array}{l}\text { Scenic area } \\
\text { supporting }\end{array}$ \\
\hline VIII & + & + & - & $\begin{array}{l}\text { Tourist complexes are generally located at urban fringes and } \\
\text { characterized by excellent market towns, abundant resources, diverse } \\
\text { services, poor rural environments, high investment and strong } \\
\text { endogenous dynamics. Due to industrial development, scenic spots and } \\
\text { townships have gradually expanded, residential areas have changed } \\
\text { frequently and new tourist towns have emerged. With the development } \\
\text { of urbanization, tourist attractions have gradually intensified, leisure } \\
\text { vacation industries have become concentrated in new towns and } \\
\text { villages have been integrated. }\end{array}$ & & Tourist complexes \\
\hline
\end{tabular}

Note: $\triangle$ represents attractions (A); represents towns $(\mathrm{T}) ; \quad$ represents the overall environment or rural background $(\mathrm{R}) ; \mathcal{H}$ represents original villages or residential areas; of tourist attractions; represents development directions of towns; represents evolution results; "+" represents superiority; "-" represents inferiority.

Space combinations that are not suitable for rural tourism development are scattered across the fifth quadrant $(\mathrm{A}-, \mathrm{T}+, \mathrm{V}-)$, the fourth quadrant $(\mathrm{A}-, \mathrm{T}+, \mathrm{V}-)$, and the sixth quadrant $(\mathrm{A}-, \mathrm{T}+, \mathrm{V}-)$. The fifth quadrant lacks typical tourist attractions and undergoes intensive real estate development and urban construction activities. Although it has formed rich commercial areas, the rural environment is seriously damaged due to chaotic spatial orders. The fourth quadrant uses agriculture as the major activity in the short-term due to the well-preserved rural environment and poor material conditions. The sixth quadrant is mainly new rural construction areas where the ecological environment and rural civilizations are damaged to a certain extent and the materials needed for tourism development are insufficient.

With the development of the tourism industry, the five spatial patterns of ATV elements have shown some common evolution features: 
- Tourism attractions highlight pluralistic and whole-territory features. Tourism resources expand gradually to the all-around vision. New resources not only include traditional tourist attractions, but also cover excellent rural environments, ample recreational activities, commercial services and landscape images.

- The concentration of service towns has advanced the urbanization of rural settlements. As the centers of the tourism industry and the suppliers of tourist facilities, tourist towns are necessary conditions for developing tourism urbanization. As is shown in the third and seventh quadrants, the existing supporting services do not meet market demands and will eventually form new industrial agglomerations near the existing settlements or new tourist areas.

- Villages (V) are landscape image areas that have diversified traditional rural benefits. Even if there is no unique high-quality tourist attraction, beautiful rural images can serve as unique environmental resources for leisure-time and holidays (the second quadrant). With the development of the leisure economy, traditional farming and breeding industries have transitioned into leisure agriculture. Part-time agriculture has become an important way to develop the local tourism economy, and an excellent rural environment has become the foundation for landscapes for developing tourist towns.

\subsection{The Single-Kernel Spatial Reconstruction Model}

As Reynolds [46] said, the value of tourism space depends on the "experience [of] diversity and local influence". Influenced by Gunn's tourism destination zone (TDZ) [32] and the spatial pedigree structure of ROS [31], combined with the common features extracted in Table 1, this paper puts forward a single-kernel spatial reconstruction model, which is an exploration of the spatial problem of rural tourism destinations in China. The spatial reconstruction model of rural areas should consider the economic efficiency of methods of utilizing the various spaces and highlight the importance of core service areas (or towns) with independent space. Considering the hierarchy of traffic, attractions and service facilities as well as the differences in demands between local residents and foreign tourists for ATV spaces, the reconstruction model based on the ATV perspective should be ensured while also ensuring that local environments are not influenced by economic behaviors, as shown in Figure 4 .

In the reconstruction model, the layout strategies of the ATV elements are as follows:

(1) Boundary and integration: A, T and V, which interact with each other and maintain relatively independent boundaries, assume different tourism activities and spatial functions. They are connected by four-level traffic corridors and combined into a whole tourism destination. Rural settlements (V) and agricultural land are also given the tourism value. Boundaries of spatial elements are used to describe the progressive process of visual field purification. They reveal the definitions, meanings, functions and roles of the three spatial organizations in cultural practices. The boundaries of spatial elements are reproducible. They can be segmented by natural and artificial landscapes and can transform resources in rural areas into rural power.

(2) Activity spectrum and single-kernel space: A spectrum that states the intensity of interference from human activities is needed, so as to achieve collaborative space with aesthetic gradients (Influenced by the ROS theory, it is proposed that different spatial elements should correspond to different human activity intensity.) It can be seen from Figure 1 that $T$ serves as the gathering place of service elements and undertakes the most intensive human activities. Nevertheless, towns should not develop without limit. Both the construction land and the population size should be strictly controlled and the (resident or transient) population capacity should comply with regulations about urban population forecasting. Governments of small towns should adopt prediction methods for resource and environment carrying capacity and make regulations according to the tourism development level. They should ensure the sufficient supply of service facilities without reducing the overall environmental quality. Small towns not only act as the suppliers of tourism facilities, but also create rich and layered spaces for public activities. 
(3) Classification and capacity: The spatial reconstruction model continuously specifies the classification of villages, small towns and tourism attractions during operations. It emphasizes that the classification of attractions is to better classify and control the capacity of tourism (i.e., heritage protection areas, traditional attractions relying on nature and culture, and new tourist attractions) and to provide different experiences for tourists with different needs.

(4) Village and landscape: In addition to the visual value that is expressed by the land, air, water and other landscape resources, the current situation of villages deserves greater attention. For instance, strict ecological policies should be made for ecologically vulnerable areas. Under the gestalt aesthetic system, both the structure and form of villages can be read as symbols of rural cultural images (i.e., the pastoral, the georgic, the exotic, the sublime and the picturesque). The implementation of spatial strategies requires greater attention to the rural livelihood strategies and the changes in residents' identities, as well as the cultural contributions of residents to the tourism economy, which can help achieve the ultimate goal of rural modernization.
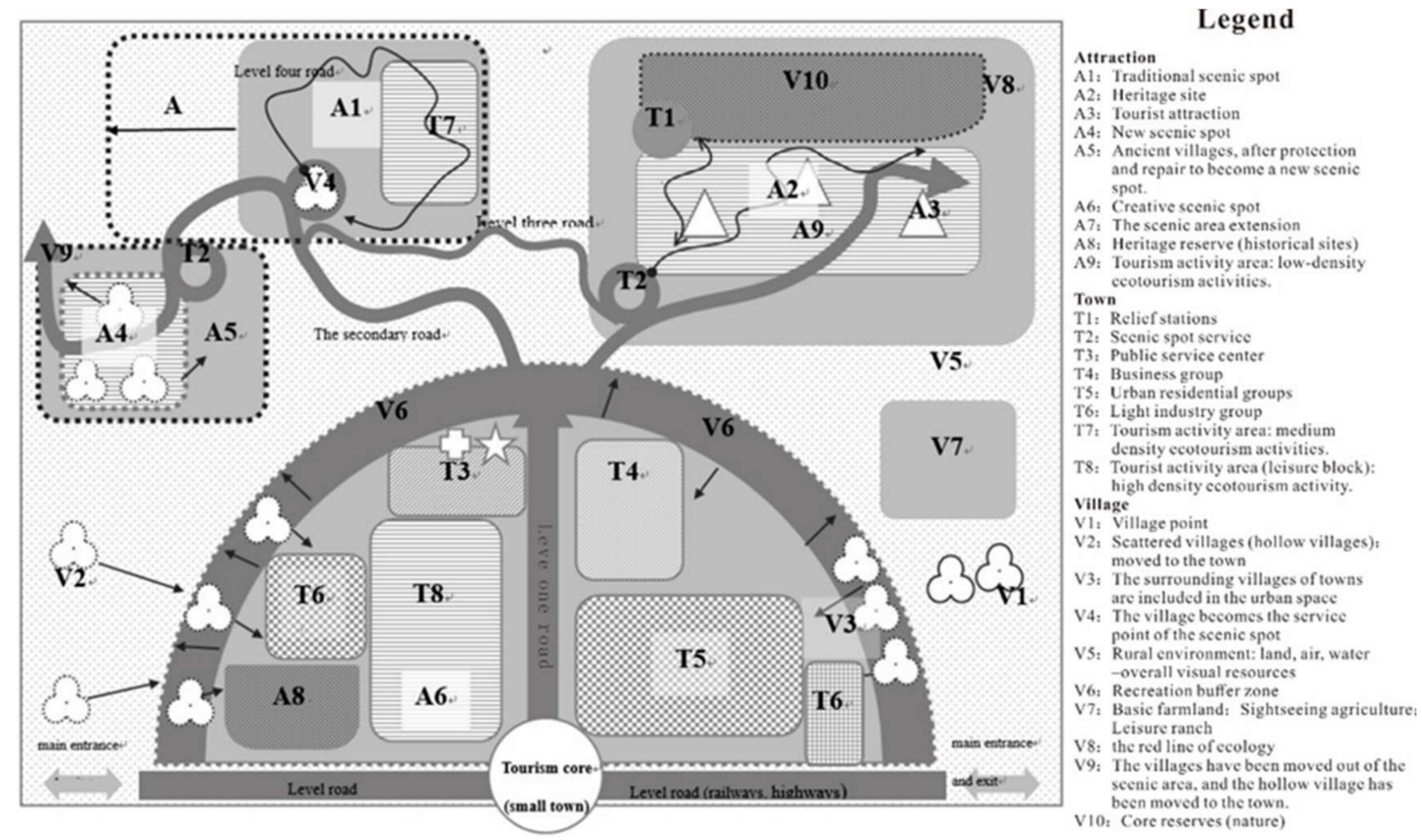

Figure 4. The single-kernel spatial reconstruction model of rural tourism destinations. Note: The semicircular areas represent service areas (or towns) where rural tourism develops. These service areas (towns) may have cultural heritage landscape areas, especially ancient towns, in addition to areas such as: New types of residential communities; handicrafts, agricultural and sideline product processing areas; creative blocks; and, public and commercial supporting services. $\mathcal{W}$ represents villages; dashed lines represent demolition/relocation; solid lines represent central villages (retention); solid lines with dotted lines represent reconstructed areas.

According to the situation of the rural environment in China, villages are divided into four categories: Expansion-oriented villages, demolition-oriented villages, relocation-oriented villages and reconstruction-oriented villages. The expansion-oriented villages generally have advantages in location and the market. Significantly influenced by urbanization, they tend to consider expanding into service towns. Demolition-oriented villages are significantly withered. Governments have encouraged natural villages with no more than three households and those located in natural/cultural heritage protection zones, or areas with frequent geological disasters and poor water and transportation facilities, to relocate residents to suitable residential or urban areas. The residents can also construct new villages in suitable areas. Spatial integration has become increasingly prominent due to the 
emergence of rural tourism. Regional villages or rural extension areas have emerged due to the improvement of roads and the development of related industries [47]. Relocation-oriented and reconstruction-oriented villages, as an important foundation of rural landscapes, have significant cultural resources and industrial advantages. Such villages can become important places for folk tourism activities after being reasonably reconstructed [48].

\section{Rural Spatial Reconstruction Practices}

\subsection{Research Methods and Data Sources}

The focus on Mufu Township began with two surveys on the overall planning for tourism development of Mufu Township in 2009 and 2014. To achieve the stated research purposes, a total of eight field surveys were carried out between February 2009 and May 2015. In addition, communication with interviewees was maintained both before and after the surveys, so as to prevent problems such as data insufficiency and data loss. The overall research process is shown in Table 2.

Table 2. The overall research process.

\begin{tabular}{cll}
\hline Investigation Time & \multicolumn{1}{c}{ Nature of Work } & Place \\
\hline 8 Feb 2009-12 Feb 2009 & Planning research & The Grand Canyon, Mufu Town and Tunbao Village \\
\hline 3 Oct 2009-10 Oct 2009 & Research and report & Mufu Town, Mugong Village and Yingshang Village \\
\hline 7 May 2010-12 May 2010 & Discussion and research & The Grand Canyon, Mufu Town and Maanlong \\
\hline 8 Mar 2011-11 Mar 2011 & Research and interview & Mufu Town and Gaotai Village \\
\hline 20 Jun 2012-20 Jun 2012 & Field research & Damiao Village and Qianshan Village \\
\hline 11 Sep 2013-15 Sep 2013 & Research and discussion & Mufu Town, the Grand Canyon and Yingshang Village \\
\hline 16 Jul 2014-22 Jul 2014 & Planning research & $\begin{array}{l}\text { The Grand Canyon, Qianshan Village, Maanlong and Nverzhai } \\
\text { Service Center }\end{array}$ \\
\hline 20 May 2015-29 May 2015 & Interview, questionnaire and discussion & $\begin{array}{l}\text { Mufu Town, the Grand Canyon, Yingshang Village, Mugong Village } \\
\text { and Nverhu }\end{array}$ \\
\hline 2 Feb 2016-12 Feb 2016 & $\begin{array}{l}\text { Telephone interview, online interview and } \\
\text { data collection }\end{array}$ & $\begin{array}{l}\text { Government officials, tourists, residents, foreign operators and art } \\
\text { performers in Mufu Township }\end{array}$ \\
\hline
\end{tabular}

The research mainly uses qualitative methods such as non-participant observation, participant observation and in-depth interviews. Mufu Town (Nverzhai Service Center), the Grand Canyon and Yingshang Village are considered the core research areas, representing the three spatial organizations A, $\mathrm{T}$ and $\mathrm{V}$ separately. The peripheral villages and other attractions are mainly studied by using scatter point analysis. This paper is written on the basis of the interviews with 34 interviewees, including residents of Mufu Town, villagers in the scenic area, village cadres, elites, government officials, officers of private cooperatives and local experts. Certainly, it is necessary to reflect on the objectivity of the research data due to the subjective evaluation and complex social networks in the research.

The basic data can be divided into two parts: Data concerning local social development and data concerning land use changes in Mufu Township between 2006 and 2016. The first type of data is obtained from public annual statistical reports on Mufu Township or Enshi Grand Canyon, as well as the discussions with the managers, the interviews with local villagers and the long-term observations. The second type of data is analyzed on the basis of Landsat 8 OLI remote sensing images, which provides the basis for the research on spatial structural changes. The author analyzes land use changes in Mufu Township between 2006 and 2016, employs quadratic polynomial and bilinear interpolation for geometric correction, and performs radiometric correction according to the image metadata. The projections of spatial elements are adjusted according to the regional realities and the research needs. Finally, Arcgis (10.2, ESRI, Redlands, CA, USA) and CAD (2016, Autodesk, San Rafael, CA, USA) are introduced to map for the changes in spatial elements.

\subsection{Case Summary}

Mufu Township is located in the northwest of Enshi City and situated in the central area of the Grand Canyon Scenic Spot. It is $61 \mathrm{~km}$ away from Enshi City in the southeast, $125 \mathrm{~km}$ away 
from Chongqing Fengjie in the north, and $40 \mathrm{~km}$ away from the Tenglongdong Scenic Spot in the southwest. Mufu Township set up offices on 10 December 2008 to assume the same responsibilities as the Enshi Grand Canyon Scenic Spot Management Office. The office administers five villages, one neighborhood committee, 5049 households and 26,100 people. Mufu Township covers an area of 180 square kilometers with an average altitude of $1000 \mathrm{~m}$, an annual average temperature of $15.5^{\circ} \mathrm{C}$, a frost-free period of 260 days and $70 \%$ forest coverage. The climate is mild and rainfall is abundant. Mufu Township is rich in natural resources (especially tourism resources and mineral resources) such as high-quality rice, flue-cured tobacco, alpine herbs, tea and fruits. The magnificent landscapes of Enshi Grand Canyon are layered. The Qingjiang River and Yunlong River run through the whole territory. Since 2009, when Yichang-Wanzhou Railway and Shanghai-Chengdu Expressway were opened, Mufu Township has adopted the slogan "develop all villages into tourist attractions, develop all households into hotels and develop all residents into tourism participants". Mufu Township has witnessed a rapid increase in its tourism industry and shown distinctive features just as the slogan "the Second Nature". The original villages have been gradually alienated due to the diversity of land usage and the geographical state has become increasingly fragmented due to the modern disintegration of traditional villages and the neglect of ecological environments and humanistic orders (Figure 5). The original settlements have been scattered across the region, increasing the construction costs of modern rural infrastructure. The original ecological landscapes have been seriously damaged due to the mixed use of tourism-used land and urban construction land, the unclear boundaries of tourist attractions and new rural reconstruction along Tun-Yu Road and Chuan-En Highway. The southeastern region of the Grand Canyon and northern region of the former tourist center have become agglomerations of tourism real estate (Nverzhai Resort) in recent years. Artificial towns have formed under the influence of leisure vacation. Although this business format best represents the layout of service facilities in domestic tourist attractions, it is detrimental to the rural environment and worthy of being reflected. The cross-border space caused by rural tourism (and real estate) is universal throughout the country, as are the spatial conflicts among tourist attractions, villages and small towns. Therefore, it is especially important to reflect on space integration in rural reconstruction research.

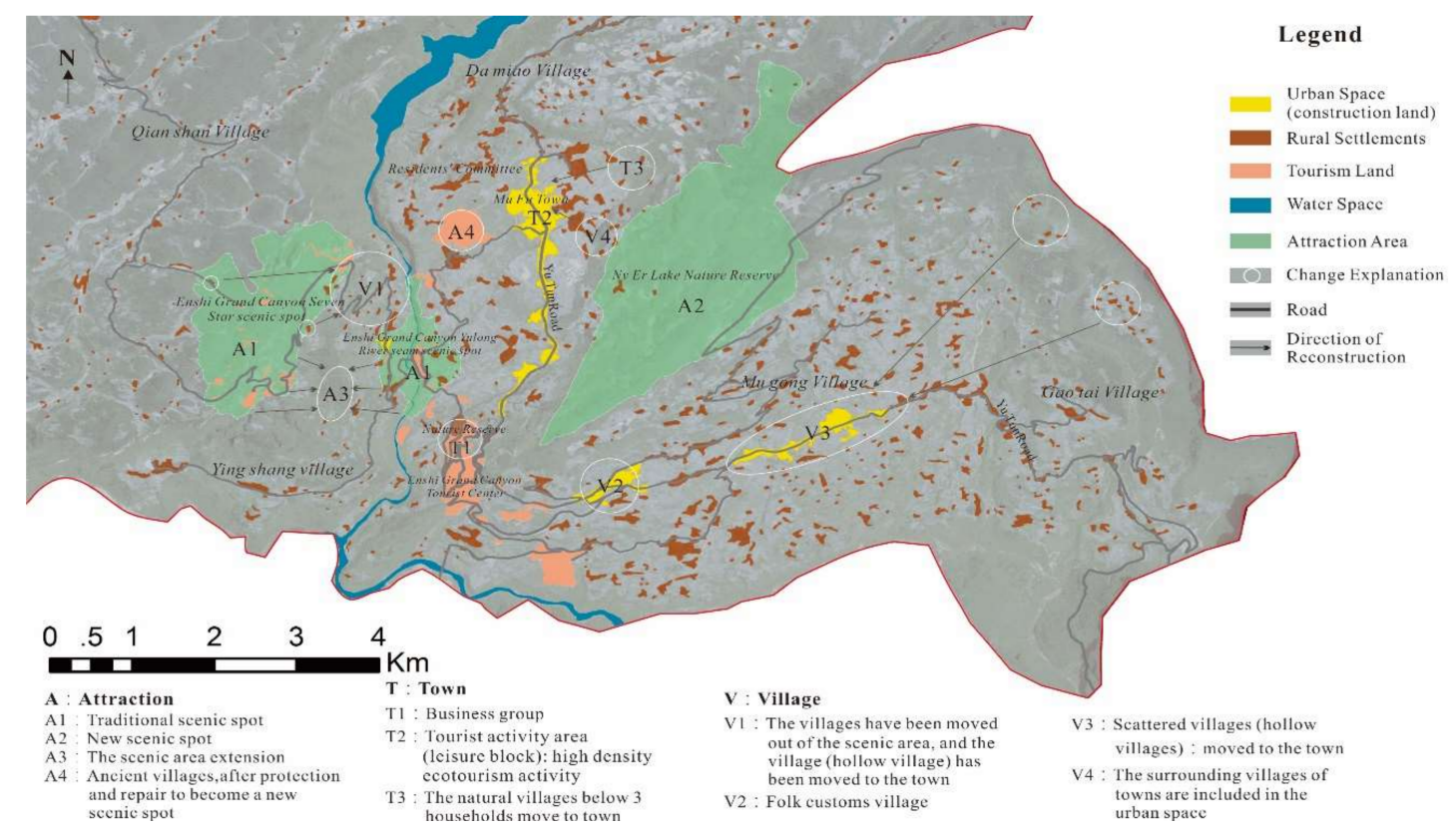

Figure 5. The status of space fragmentation in Mufu Township. Note: ARCGIS10.1 was adopted to classify and analyze related remote sensing images. Satellite images come from Landsat 8 OLI and the spatial resolution of the panchromatic band is $2 \mathrm{~m}$. Land use types include construction land, residential area, farmland, tourism-use land, and woodland. 


\subsection{Spatial Reconstruction Results of Mufu Township}

Mufu Township was reconstructed according to the single-kernel gestalt construction model based on the ATV perspective in Figure 4, the spatial layout of which is shown in Figure 6. The critical collaboration of $\mathrm{A}, \mathrm{T}$ and $\mathrm{V}$ contributes to the transformation and recombination among spatial elements:

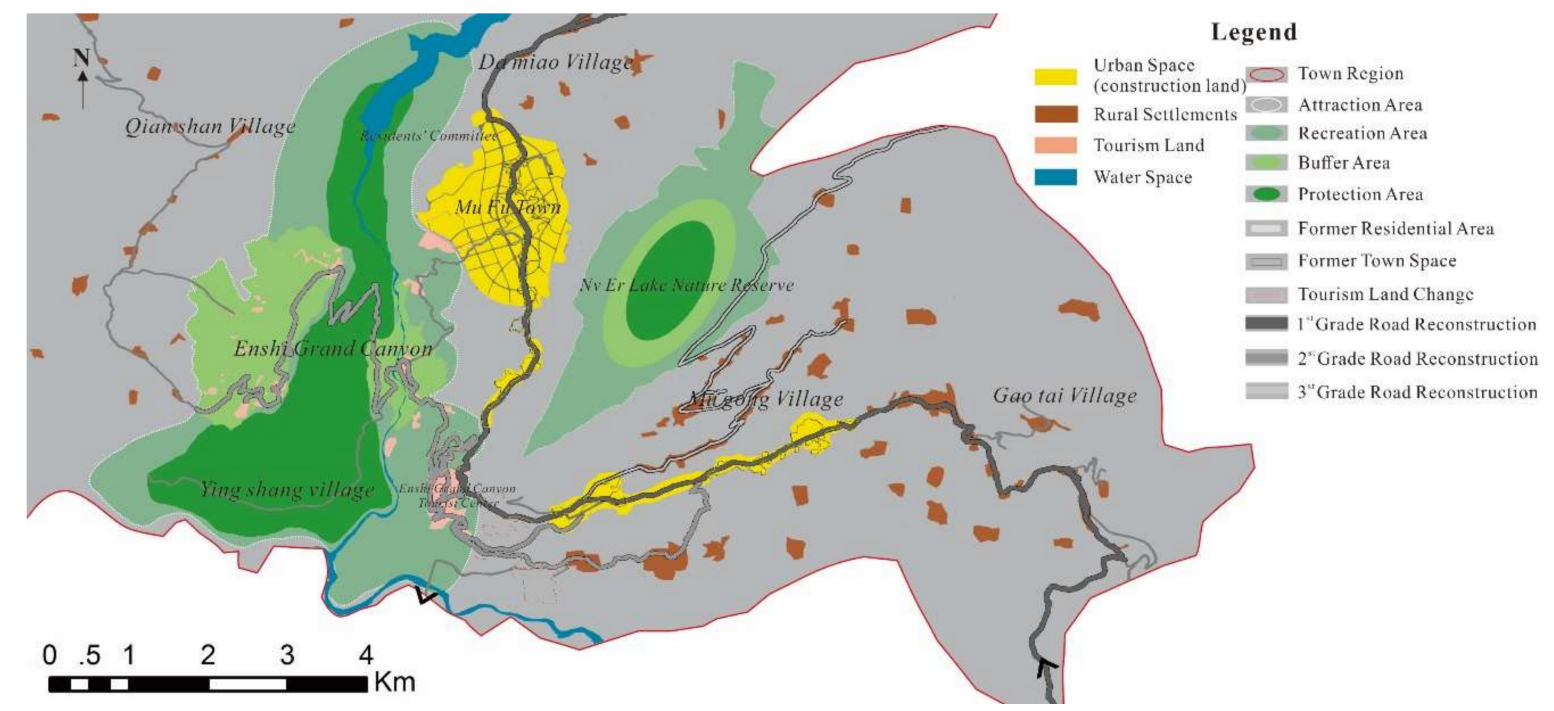

Figure 6. An analysis of reconstruction strategy for rural space in Mufu Township.

(1) A, including the Enshi Grand Canyon Scenic Spot and the Nverhu Protected Area, is situated on both sides of Tun-Yu Road. The Grand Canyon is an expansion of the former Qixingzhai and Yunlong River Crack. The former Visitor Center Service Station in the southeast relies on Yingshang Village to transform the service area. The Grand Canyon has been upgraded to an AAAAA tourism destination after spatial reconstruction and divided into four spatial zones: Natural reserves, geographic heritage protection areas, sightseeing areas and recreational areas. (Until now, China has adopted the classification method of resources "Classification, investigation and evaluation of tourism resources Standard" (GB/T 18972-2017) [49], and the star rating of scenic spots has been unified under the management of the National Tourism Administration, which has a strong economic and political significance.) The Nverhu Protected Area, which is divided into core protected areas and outer buffer zones, accepts responsible sightseeing. The tourist attractions consist of two different scenery resources and present the spatial layout of concentration in small scale and dispersion in large scale.

(2) $\mathrm{T}$ focuses on the expansion and transformation of Mufu Town. Mufu Town has been developed into a service distribution center in the Grand Canyon. The town population increased from 4000 in 2009 to 11,0000 in 2015, and the built-up area trebled as at the end of 2015, involving a total of 1697 dwellings. Mufu Town was named as a national-level tourist town in 2015 for its unique ethnic customs, strong regional characteristics and perfect tourism functions. The southeastern region was adjusted around the original MuGong Village. In other words, Nverzhai has had part of its facilities moved to Mugong Village to create a custom tourism attraction in the south. The small town has become a special space with frequent and strong human disturbance, has provided tourism supporting services and served as the distribution center, thereby being referred to as a vital symbol of the whole cultural landscape.

(3) V mainly relocates the residents in five natural villages and multiple scattered settlements to three central villages and Mufu Town. Along with the development of tourist attractions, some residents have been relocated within the scenic spot, and the residential areas along the highway have been transformed into folk houses. A total of 406 dwellings have been reconstructed. 
Mufu Township has completed more than 8,000 acres of landscape planting, developed more than 150 farmhouses (including 44 Five-star farmhouses) and established 22 agricultural cooperatives, which specialize in manufacturing tea, grapes, peonies and lavender, and support low-density heritage-style tourism. Rural residents in Mufu Township have become the main components of the tourism industry. Residents' per capita income has increased significantly. The annual income of tourism operators is about CNY 130,000.

It is the precondition of the improvement of the overall rural environment to upgrade road levels, construct new village roads and complete the Ecological Corridor of the Yellow Crane Tower. Two regional entrances and exits have been added to evacuate tourists in peak seasons. The key to a reasonable rural layout is to upgrade the Tun-Yu Road and the Chuan-En Highway and improve the road connection between villages.

The paper aims to explore the reconstruction of orders in new rural tourism spaces. Rural areas have become the all-around vision of tourism attractions, small towns and villages. Rural spatial reconstruction not only refers to the integration of material spaces. It also involves the process of coordinating between human activities and material spaces and reconciling spatial orders with social orders. For example, the reconstruction of Mufu Township triggered population movement, changed residents' identities and influenced their ideologies.

\section{Conclusions and Future Study}

Based on the theoretical and practical explorations into rural spatial management, this paper for the first time explores the spatial composition and the relations between tourist attractions, towns and villages. The conclusions are as follows:

(1) Five spatial models of tourism urbanization are concluded on the spatial benefit trade-offs within the ATV. A, T and V are independent and interdependent. Although there are geographical differences among them, they have the same spatial evolution characteristics: A presents the characteristics of diversification and territoriality; $\mathrm{T}$ promotes the urbanization of rural settlements; and $\mathrm{V}$ highlights landscape images and diversifies traditional rural structures.

(2) The single-kernel reconstruction model based on the ATV perspective emphasizes the moderate spatial concentration and exerts the scale agglomeration effects, so as to prevent the negative impacts from decentralized development and improve the quality of the rural environment. The three spatial organizations $\mathrm{A}, \mathrm{T}$ and $\mathrm{V}$ hold different tourism activities and assume different spatial functions. The three spaces of $\mathrm{A}, \mathrm{T}$ and $\mathrm{V}$ are set to possess different tourism activities and functions. $\mathrm{A}$ is divided into high-, medium- and low-density tourism activity areas according to the resource types. In the space of $\mathrm{T}$, tourism service facilities are clustered in areas suitable for urban construction, and these areas are eventually developed into tourist towns, which provide public services for both local residents and tourists. In addition, some rural settlements are retained and restored as tourism villages while others are reconstructed into small new towns.

(3) Based on the analysis of the current space situation in Mufu Township, this paper has constructed a brand new spatial layout according to the single-kernel reconstruction model. The results showed that Mufu Township has been revived. The Grand Canyon has been upgraded to an AAAAA tourism destination and multiple tourism attractions (represented by the Nverhu Protected Area) have been developed around it. Mufu Town has been transformed into a famous tourism town, due to the concentration of commercial and public services, the increase of population and the upgrade of the tourism industry. The surrounding villages have been relocated in accordance with natural economic conditions. The central villages have been built into landscape supplementary areas. Mufu Township has finally formed a spatial coordination case-study area, which is attributed to the reconstruction of $\mathrm{A}, \mathrm{T}$ and $\mathrm{V}$. 


\section{Future Study Direction}

Rural revitalization is a large-scale project that involves changes in industrial structure, employment structure, rural settlement patterns, the social/cultural landscape, etc. [50-52]. This paper has only discussed the reconstruction of spatial structure. It did not consider social relationships or land policy changes caused by rural reconstruction, although these are important parts of rural revitalization. For the long term, the contents and tasks of spatial management will change with socio-economic development, and the spatial reconstruction models will be constantly revised. Therefore, the regional and temporal characteristics of spatial reconstruction deserves further attention. In addition, it will be necessary in the future to carry out innovative research concerning spatial reconstruction techniques and systematic dynamic monitoring, pre-warning and scientific regulation.

Although the single-kernel model based on the ATV system applies to tourism urbanization areas, the five different spatial patterns may experience different spatial evolution processes (Table 1). Therefore, it is necessary to adjust the model according to the actual situation. In this paper, the model is adopted to verify the reconstruction process of urban new areas taking Mufu Township as an example. Future studies should focus on verifying other spatial patterns.

Author Contributions: The first author (H.T.) contributed in writing original drafts, innovative ideas, data collection, formal analysis, and methodology. The second author (Z.H.) and the third author (F.R.) contributed in analysis, review and map editing.

Funding: This research was funded by the National Social Science Foundation of China (No. 17ZDA165), and the staged achievements of Collaborative and Innovative Center for Marxism and Nationalism Education (2016BJ05MZDX).

Conflicts of Interest: The authors declare no conflict of interest.

\section{References}

1. Lefebvre, H. The Production of Space; Wiley-Blackwell: Hoboken, NJ, USA, 1992; ISBN 9780631181774.

2. Marsden, T.; Lowe, P.; Whatmore, S. Rural Restructuring: Global Processes and Their Responses; David Fulton: London, UK, 1990; ISBN 1853461113.

3. Woods, M. Rural; Taylor and Francis: London, UK, 2010; ISBN 9781136919176.

4. Rasoolimanesh, S.M.; Ringle, C.M.; Jaafar, M.; Ramayah, T. Urban vs. rural destinations: Residents' perceptions, community participation and support for tourism development. Tour. Manag. 2017, 60, 147-158. [CrossRef]

5. Wu, B.H.; Gao, J. Revitalizing traditional villages through rural tourism: A case study of Yuanjia Village, Shaanxi Province, China. Tour. Manag. 2017, 63, 223-233. [CrossRef]

6. Mullins, P. Tourism Urbanization. Int. J. Urban Reg. Res. 2010, 15, 326-342. [CrossRef]

7. Li, L.H. Balancing Rural and Urban Development: Applying Coordinated Urban-Rural Development (CURD) Strategy to Achieve Sustainable Urbanisation in China. Sustainability 2017, 9, 1948. [CrossRef]

8. Vaugeois, N. Rural tourism: An international perspective. Ann. Tour. Res. 2015, 54, 225-226. [CrossRef]

9. Shucksmith, M. Re-imagining the rural: From rural idyll to Good Countryside. J. Rural Stud. 2016, 7, 19. [CrossRef]

10. Hoggart, K.; Paniagua, A. What rural restructuring. J. Rural Stud. 2001, 17, 41-62. [CrossRef]

11. Sun, H.; Liu, Y.S.; Xu, K.S. Hollow Villages and Rural Restructuring in Major Rural Regions of China: A Case Study of Yucheng City, Shandong Province. Chin. Geogr. Sci. 2011, 21, 354-363. [CrossRef]

12. Mitchell, C.J.A. Entrepreneurialism, commodification and creative destruction: A model of post-modern community development. J. Rural Stud. 1998, 14, 273-286. [CrossRef]

13. Harvey, D. The Urbanization of Capital; The Johns Hopkins University Press: Baltimore, MD, USA, 1985; ISBN 9780801831447.

14. Frisvoll, S. Power in the production of spaces transformed by rural tourism. J. Rural Stud. 2012, 28, 447-457. [CrossRef]

15. Hall, D.R. Tourism development and sustainability issues in Central and South-eastern Europe. Tour. Manag. 1998, 19, 423-431. [CrossRef] 
16. Wang, Z.C.; Li, J.L. Study on the tour industry spatial layout of the Yangtze River delta. Econ. Geogr. 2006, 2, 83-86. [CrossRef]

17. Li, W.W.; Cao, K.; Church, R.L. Cyberinfrastructure, GIS, and spatial optimization: Opportunities and challenges. Int. J. Geogr. Inf. Sci. 2016, 30, 427-431. [CrossRef]

18. Howard, E. Garden Cities of To-Morrow; The MIT Press: Cambridge, MA, USA, 1965; ISBN 9780262580021.

19. Farrell, B.H.; Twining-Ward, L. Reconceptualizing tourism. Ann. Tour. Res. 2004, 32, 274-295. [CrossRef]

20. Lobley, M.; Potter, C. Agricultural change and restructuring: Recent evidence from a survey of agricultural households in England. J. Rural Stud. 2004, 20, 499-510. [CrossRef]

21. Nelson, P.B. Rural restructuring in the American West: Land use, family and class discourses. J. Rural Stud. 2001, 17, 395-407. [CrossRef]

22. Kiss, E. Rural restructuring in Hungary in the period of socio-economic transition. GeoJournal 2000, 51, 221-233. [CrossRef]

23. Tuan, Y.F. Space and Place: The Perspective of Experience; University of Minnesota Press: Minneapolis, MN, USA, 2001; ISBN 9780816638772.

24. Carter, E.D.; Guzmán, G.; Silva, B. Migration, Acculturation, and Environmental Values: The Case of Mexican Immigrants in Central Iowa. Ann. Assoc. Am. Geogr. 2013, 103, 129-147. [CrossRef]

25. Daly, S. Producing healthy outcomes in a rural productive space. J. Rural Stud. 2015, 40, 21-29. [CrossRef]

26. Wang, R.; Liu, J.M.; Chen, T.; Tian, D.J. Distribution of recreational area in suburban metropolis: A case study of Beijing. Acta. Geogr. Sin. 2010, 65, 745-754. [CrossRef]

27. Sigala, M. Managing Tourism Destinations. Ann. Tour. Res. 2008, 35, 836-838. [CrossRef]

28. Brown, K.; Turner, R.K.; Hameed, H.; Bateman, I.J. Environmental carrying capacity and tourism development in the Maldives and Nepal. Environ. Conserv. 1997, 24, 316-325. [CrossRef]

29. Shaker, R.R. A mega-index for the Americas and its underlying sustainable development correlations. Ecol. Indic. 2018, 89, 466-479. [CrossRef]

30. Tosun, C. Expected nature of community participation in tourism development. Tour. Manag. 2006, 27, 493-504. [CrossRef]

31. Butler, R.W.; Waldbrook, L.A. A new planning tool: The Tourism Opportunity Spectrum. J. Tour. Stud. 1991, 2, 2-14.

32. Gunn, C.A. Destination zone fallacies and half-truths. Tour. Manag. 1982, 3, 263-269. [CrossRef]

33. Ahn, B.Y.; Lee, B.K.; Shafer, C.S. Operationalizing sustainability in regional tourism planning: An application of the limits of acceptable change framework. Tour. Manag. 2002, 23, 1-15. [CrossRef]

34. Tao, H.; Liu, J.M.; Yu, H.; Zhu, H. The conceptual model of the spatial restructuring in the region of tourism urbanization: Acase study of Mayangxi Ecotourism Area. Geogr. Res. 2017, 36, 1123-1137. [CrossRef]

35. Huang, X.; Bao, J.G.; Wall, G. Chinese ecotourism opportunities spectrum (CECOS). Sci. Geogr. Sin. 2006, 26, 5629-5634. [CrossRef]

36. Buzinde, C.N.; Manuel-Navarrete, D. The social production of space in tourism enclaves: Mayan children's perceptions of tourism boundaries. Ann. Tour. Res. 2013, 43, 482-505. [CrossRef]

37. Zhang, L.; Liu, Y. An Analysis on Man-Land Relationship of Eastern China. Acta Geogr. Sin. 2004, 59, 311-319. [CrossRef]

38. Tao, H.; Liu, J.M.; Deng, Y.; Du, A. Tourism sectorization opportunity spectrum model and space partition of tourism urbanization area: A case of the Mayangxi ecotourism area, Fujian province, China. J. Mt. Sci. 2017, 14, 595-608. [CrossRef]

39. Wang, D.G.; Lu, L.; Chen, T.; Liu, C.X. A Study on the Evolement of Resort System Spatial Structure of the Pole-Axis Theory-A Case of Tourism Region of Hulun Buir-Aershan. Econ. Geogr. 2005, 25, 904-909. [CrossRef]

40. Dear, M.J.; Wolch, J.R. Landscapes of Despair; Princeton University Press: Princeton, NJ, USA, 1987; ISBN 9780691025407.

41. Marsden, T. Beyond agriculture? Regulating the new rural spaces. J. Rural Stud. 1995, 11, 285-296. [CrossRef]

42. Ashihara, Y. The Aesthetic Townscape; The MIT Press: Cambridge, MA, USA, 1984; ISBN 978-0262510318.

43. Qian, M.; Pu, L.J.; Zhang, J.; Zhang, M. Urban spatial expansion characteristics in China's rapid urbanization region-A case study of SXC Region. Int. J. Geosci. 2013, 4, 1365-1375. [CrossRef]

44. Yang, D.T. China's land arrangements and rural labor mobility. China Econ. Rev. 1997, 2, 1011-1115. [CrossRef] 
45. Chen, J.; Yang, X.J.; Wang, Z.Q.; Zhang, L.X. Vulnerability and Influence Mechanisms of Rural Tourism Socio-ecological Systems: A Household Survey in China's Qinling Mountain Area. Tour. Trib. 2015, 30, 64-75. [CrossRef]

46. Reynolds, P.C.; Braithwaite, D. Towards a conceptual framework for wildlife tourism. Tour. Manag. 2001, 22, 31-42. [CrossRef]

47. Huang, Z.F.; Lu, L.; Su, Q.; Zhang, J.H.; Sun, J.X.; Wan, X.C.; Jin, C. Research and development of rural tourism under the background of new urbanization: Theoretical reflection and breakthrough of predicament. Geogr. Res. 2015, 34, 1409-1421. [CrossRef]

48. Knight, J. Rural Revitalization in Japan: Spirit of the Village and Taste of the Country. Asian Surv. 1994, 34, 634-646. [CrossRef]

49. Classification, investigation and evaluation of tourism resources (GB/T18972-2017). Available online: http:/ / www.gb688.cn/bzgk/gb/newGbInfo?hcno=B8AFA5B524438117E00F3BC259B6831C (accessed on 27 July 2018).

50. Fei, X.T. The Path of Urban and Rural Development in China; Shanghai People's Publishing House: Shanghai, China, 2016; ISBN 978-7208138599.

51. Xi, J.C.; Zhao, M.F.; Ge, Q.S.; Kong, Q.Q. Changes in land use of a village driven by over 25 years of tourism: The case of Gougezhuang village, China. Land Use Policy 2014, 40, 119-130. [CrossRef]

52. Shaker, R.R. Examining sustainable landscape function across the Republic of Moldova. Habitat Int. 2018, 72, 77-91. [CrossRef]

(C) 2018 by the authors. Licensee MDPI, Basel, Switzerland. This article is an open access article distributed under the terms and conditions of the Creative Commons Attribution (CC BY) license (http:/ / creativecommons.org/licenses/by/4.0/). 